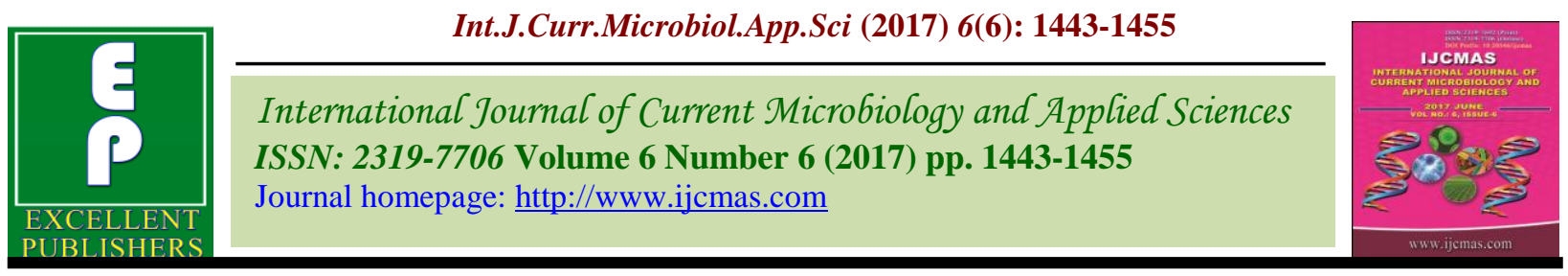

Original Research Article

https://doi.org/10.20546/ijcmas.2017.606.169

\title{
Mapping of QTLs for Grain Yield and its Component Traits under Drought Stress in Elite Rice Variety of Assam, India
}

\author{
Rahul K. Verma ${ }^{1 *}$, S.K. Chetia ${ }^{2}$, P.C. Dey ${ }^{3}$, A.R. Baruah ${ }^{4}$ and M.K. Modi ${ }^{5}$ \\ ${ }^{1}$ Department of Agricultural Biotechnology, Jorhat, India \\ ${ }^{2}$ Regional Agricultural Research Station, Titabar, India \\ *Corresponding author
}

\begin{abstract}
A B S T R A C T
\end{abstract}
Drought is one of the major abiotic stress that limits rice production in Assam, India. A traditional drought tolerant local cultivar 'Banglami' was crossed with a high yielding rice variety 'Ranjit' and $180 \mathrm{~F}_{2}$ plants were raised. The 110 polymorphic SSR markers were used for genotyping of $\mathrm{F}_{2}$ plants. Out of which, 88 fitted the expected Mendelian segregation, whereas $22(20.0 \%)$ significantly deviated from it $(\mathrm{P}<0.01)$. Only 89 SSR markers could be assigned to 12 linkage groups covering a total of $1628.7 \mathrm{cM}$ of the genome. The $120 \mathrm{~F}_{2: 4}$ lines were evaluated for various yield traits under drought stress and irrigated conditions. A total of 11 QTLs were identified for grain yield and its component traits with the phenotypic variation ranging from $0.04 \%$ to $84 \%$ under both hydrological conditions. The QTL for effective booting tillers remained consistent on chromosome 6 under both conditions. The clustering of QTLs was observed for panicle length, number of chaff per panicle and spikelet fertility at the marker interval of RM253-RM30 on chromosome 6. Thus with further fine mapping of these region, it may be possible to tightly tag the QTLs for precise introgression in MAB. The two improved advanced lines (B-42 and B-106) were selected based on yield and grain quality traits under drought stress for development of drought tolerant rice variety in elite genetic background.

\section{Introduction}

Rice (Oryza sativa L.) is the most important food crop for nearly half of the world's population (Sellamuthu et al., 2011) and has got the wide range of physical adaptability. It is grown from below sea-level in Kerala upto the hills of North-Eastern in India. The frequent occurrence of abiotic stress such as drought has been identified as the key factor for low productivity in the rainfed ecosystem. Worldwide, drought affects approximately 23 million ha of rainfed rice. Among different rainfed regions, eastern India, with around 13.6 million ha of drought-prone area, is the largest in the world (Vikram et al., 2011). Rice is highly sensitive to water stress at the reproductive stage (Venuprasad et al., 2007). Previously, secondary yield component traits and physiological traits were used as selection criteria for improving grain yield under drought in rice (Jongdee et al., 2002).

However, desired improvement in grain yield could not be achieved through selection for secondary traits. Hence, grain yield under drought stress has been suggested as a selection parameter in drought breeding 
(Bernier et al., 2008). Many QTLs have been identified (Kumar et al., 2014) and breeding lines have been developed for upland and rainfed lowland conditions (Verulkar et al., 2010) by using this approach. However, this is the first report on QTL mapping for various yield traits and development of improved advanced breeding lines under drought stress in Assam rice cultivars.

The North- Eastern India, covering Assam and other states, is considered to be one of the important hot spots of rice genetic diversity in the world and a potential region with extremely diverse rice growing conditions as compared to other parts of the country. It is the most important crop in Assam and covers 2.54 million $(\mathrm{M})$ ha of the total $3.3 \mathrm{M}$ ha cropped area. Traditionally, rice is grown in the state, in three overlapping seasons and is dependent on rainfall pattern. Among the three rice seasons, 'ahu' or autumn rice is grown predominantly as direct seeded under rainfed upland ecosystem during February/March to June/July. It covers $0.3 \mathrm{M}$ ha area with an average yield of less than $1000 \mathrm{~kg} / \mathrm{ha}$, the productivity ' $a h u^{\prime}$ rice is the lowest among all rice cultures of the state. The rice crop in this ecosystem encounters a number of serious problems with extremely adverse impact on productivity and among these drought cause heavy loss to the crop resulting in significant decline in yield.

The high-yielding varieties of Assam were never selected for drought tolerance because of the high rainfall situation of the state. These varieties, when exposed to drought stress because of vagaries of climate, suffer significant decline in yield. However, because of global warming and the resultant climate change scenario intermittent drought has become very common during the rice growing seasons of the state. Though some traditional drought tolerant cultivars are available, these are not very popular among the farmers due to low grain yield and undesirable plant types. Therefore, QTLs for various yield component traits and high yielding advanced breeding lines were identified under drought stress in the present study can be successfully utilized in (Marker Assisted Breeding) MAB for the development of high yielding drought tolerant rice variety.

\section{Materials and Methods}

\section{Plant materials and crossing scheme}

Banglami, a tall, early maturing, short bold grains and medium duration (120-130 days) drought tolerant cultivar, was used as a female parent. Ranjit is a semi dwarf, long duration (150-155 days), weekly photosensitive, medium slender grains and drought susceptible variety and it was used as a male parent. The cultivars, ARC10372, Sahbhagi Dhan and Nerica were used as a drought tolerant check for phenotypic. A total of $50 \mathrm{~F}_{1}$ seeds were obtained from the cross between 'Banglami and Ranjit'. $180 \mathrm{~F}_{2}$ plants were raised from selfing of true $F_{1} s$. The seeds from only $120 \mathrm{~F}_{2}$ plants were harvested (some plants were abandoned due to attack of birds and insect on the filled grains) and bulked to raise $\mathrm{F}_{3}$ plants. The $120 \mathrm{~F}_{2: 3}$ lines consisting of $1268 \mathrm{~F}_{3}$ plants were raised and harvested individually. The $120 \quad \mathrm{~F}_{2: 4}$ lines consisting of $2460 \mathrm{~F}_{4}$ plants were evaluated for various yield traits under drought stress and irrigated conditions.

\section{Phenotyping}

The $\mathrm{F}_{2: 4}$ lines were evaluated for various yield traits following Augmented Randomized Block Design under two different hydrological conditions i.e., artificial drought stress created in rainout shelter and irrigated (non-stress) conditions in the experimental field of Regional Agriculture Research Station (RARS) Titabar, during rabi season 
(December 2015 - July 2016). For drought stress, seeds were hand dibbled in dry soil. After 45 days of emergence uniform plant stand was maintained with a spacing of $20 \mathrm{~cm}$ by thinning and gap filling (Fig. 1) However, under irrigated conditions, 45-day-old seedlings were transplanted in the main field (Fig. 2). Single seedling per hill was transplanted with $20 \mathrm{~cm}$ spacing between the hills in the row. While the control plots were irrigated regularly to the field capacity, the drought stress plots were irrigated by sprinkler twice a week during establishment and early vegetative growth.

The drought stress was imposed from panicle initiation to panicle emergence period (reproductive stage) by withholding irrigation (Fig. 1). NPK fertilizers were applied at the rate of 40:20:20 kg/ha. While $\mathrm{P}$ and $\mathrm{K}$ were applied basally during sowing, $\mathrm{N}$ was applied in two splits as top dressing. Insect, fungal and weed control measures were applied periodically as required

Data on various yield traits i.e. Days to 50 per cent flowering (DTF), Plant height (PH), Number of tillers per plant (NOT), Effective booting tillers per plant (EBT), Panicle length (PL), Number of grains per panicle (NOG), Number of chaff per panicle (NOC), Spikelet fertility (SF), Grain yield (GY) per plant and Relative leaf water content (RLWC) were recorded at maturity from the trials conducted under both hydrological conditions.

\section{Statistical analysis}

Analysis of variance (ANOVA), critical difference and broad-sense heritability for all the traits among the $\mathrm{F}_{4}$ plants were estimated by using software Windostat Version 9.2 from Indostat Services, Hyderabad. The Pearson correlation among the traits was analysed by using SPSS version 15.0.
Genotyping and construction of genetic linkage Map

Genomic DNA was extracted following the protocol of Plaschke et al., (1995). The quality of DNA extracted was checked using 0.8 percent agarose gel electrophoresis and quantified using Nanodrop® ND-1000 Spectrophotometer. For PCR analysis, $10 \mu \mathrm{L}$ of reaction mixture consisting $50 \mathrm{ng}$ DNA, 1X PCR buffer, $2.5 \mathrm{mM}$ dNTPs, $20 \mathrm{pM}$ each primer and 1 unit Taq DNA Polymerase enzyme was made for PCR analysis. The amplified products were resolved in 3.5 percent agarose gel stained with ethidium bromide. A total of 350 SSR markers were screened across the parental cultivars (Banglami and Ranjit). Among these, only 110 SSR markers revealed distinct polymorphism and were used for genotyping of $180 \mathrm{~F}_{2}$ plants. Chi square test was used to compute the segregation pattern of each SSR marker against the expected ratio of 1:2:1 at 0.01 probability levels. Linkage analysis was performed by using JoinMap software (Stam, 1993) at critical LOD scores of 3 between two markers.

\section{QTL analysis}

QTLs were identified using Win QTL cartographer 2.5 (Basten et al., 2001). Interval or Composite interval mapping, LOD score of 2.5 and Kosambi mapping function were used for detection of QTLs for grain yield and its component traits under both the hydrological conditions.

\section{Results and Discussion}

Variation in the yield and its component traits

Significant variation was observed among the parents and the $\mathrm{F}_{4}$ plants for various yield traits under drought stress and irrigated 
conditions (Table 1) respectively. The large difference in the days to 50 per cent flowering was observed between the drought tolerant cultivar, Banglami (110 days) and susceptible cultivar, Ranjit (161 days) under drought stress. Early flowering under drought stress has been observed previously in some short duration rice cultivars (Lafitte et al., 2006). Many $\mathrm{F}_{4}$ plants also flowered earlier under drought stress than under irrigated conditions, some by upto 15 days. The ability of a plant to complete its life cycle before development of soil water deficits is a drought escape mechanism. Therefore, these lines can be used for development of short duration rice varieties for upland drought affected areas. In drought-prone upland areas of eastern India and Bangladesh, drought escape is an important mechanism that allows rice to produce grain despite limited water availability (Bernier et al., 2008).

The parental cultivars differed for grain yield under stress and irrigated conditions. In normal condition the grain yield of Ranjit was $25 \mathrm{gm} /$ plant however, when exposed to drought stress it came down to $4.5 \mathrm{gm} / \mathrm{plant}$, whereas, no significant reduction in the grain yield was observed for the tolerant cultivar 'Banglami'.

The variation in grain yield was also recorded among the $\mathrm{F}_{4}$ plants, it was observed more than $10 \mathrm{gm} /$ plant for $20 \mathrm{~F}_{4}$ plants. Higher broad-sense heritability for grain yield and its component traits were observed under drought stress conditions. It indicates low environmental influence on these traits and therefore, can be used in the selection of superior plants. The two $\mathrm{F}_{2: 4}$ lines (B-42 and B-106) were selected under drought stress condition using yield and grain quality traits as selection criteria. Similarly, high heritability of yield traits was also reported by Bernier et al., (2007).

\section{Correlation among the yield traits}

The values of correlation coefficient among the yield and its component traits under drought stress are presented in table 2. The delay in flowering was observed in some of the $\mathrm{F}_{4}$ plants under drought stress due to the reduction in the rate of floral development and panicle elongation (Lafitte et al., 2004), which results in significant loss in the grain yield and associated with drought susceptibility also reported by Pantuwan et al., (2002). Grain yield had significant positive correlation with number of tillers $(0.186 *)$, effective booting tillers $(0.259 * *)$, plant height $(0.240 * *)$, panicle length $(0.292 * *)$, number of grains per panicle $(0.501 * *)$ spikelet fertility $(0.463 * *)$ and negative correlation with number of chaff per panicle $\left(-0.253^{* *}\right)$ under drought stress. This showed that panicle associated traits mainly contributed towards higher grain yield. Kumar et al., (2008) also made similar observation. Suji et al., (2012) also reported the significant positive correlation of grain yield with plant height, number of effective booting tillers and spikelet fertility under drought stress. The observed yield differences between stress and irrigated conditions were mainly dependent on the capacity of plants to maintain proper seed setting under stress conditions. Though some plants were observed to have accumulated of huge biomass, the yield was quite low, which was because the inability of the plant to maintain proper seed settings. Liu et al., (2006) also reported that the main cause of yield reduction when drought stress is applied around flowering is spikelet sterility.

\section{Genotyping and linkage analysis}

A total of 110 polymorphic SSR markers across the parental cultivars were used for genotyping of $180 \mathrm{~F}_{2}$ plants (Supplementary Fig. 3a and 3b). Among 110 SSR markers, 88 
fitted for the expected Mendelian segregation (Table 1), whereas $22(20.0 \%)$ significantly deviated from it $(\mathrm{P}<0.01)$. Out of these 22 markers, only $11(50 \%)$ markers deviated towards female parent Banglami, designated as (a), 3 markers (13.6\%) toward heterozygote $(\mathrm{h})$ and $8(36.36 \%)$ markers deviated toward male parent Ranjit (b).

The observed segregation distortions may be due to the population size of only $180 \mathrm{~F}_{2}$ plants were used in the present study or abortion of gametes and zygote. It is a problem often encountered in mapping studies (Zivy et al., 1992).

According to Hackett and Broadfoot (2003) segregation distortion had very little effect both on marker order and map length. When the skewed markers were removed from the linkage analysis, there was a decrease in the number of linked markers and in the total length of some chromosomes, resulting in low coverage of the genome.

Moreover, estimation of recombination fractions among co-dominant markers is less affected by segregation distortion than that of dominant markers (Lorieux et al., 1995). Therefore, all the skewed markers were retained for linkage analysis.

Out of 110 polymorphic SSR markers, only 89 SSR markers could be assigned to 12 linkage groups (LGs) covering a total of $1628.7 \mathrm{cM}$ of the rice genome at an average marker density of $18.3 \mathrm{cM}$.

The number of markers on each linkage group ranged from 6 (LG 3, 4, 5, 6, 9, 10, 12) to 12 (LG1) and the length of each linkage group ranged from $70.7 \mathrm{cM}$ (LG3) to $264.6 \mathrm{cM}$ (LG1). The average distance between adjacent markers ranged from $11.43 \mathrm{cM}$ (LG7) to $20.05 \mathrm{cM}$ (LG1) respectively. One gap of more than $20 \mathrm{cM}$ between adjacent markers was present on each linkage group except for LG7.

According to Servin and Hospital (2004) two to four markers on a chromosome of about $100 \mathrm{cM}$ distance could provide adequate coverage of the genome on backcross programs through MAB simulation study. Therefore, the present genetic map of rice can be successfully utilised further for introgession of various QTLs identified under drought stress.

\section{QTL analysis}

A total of seven QTLs were identified on chromosome 1, 2, 6, 7 and 12 under drought stress. However, under irrigated conditions only four QTLs were identified and positioned on chromosome 6, 4 and 9 (Table $3)$.

Maximum number of five QTLs being present on chromosome number 6 under both the hydrological conditions. Although many QTLs for grain yield under drought stress was reported by Kumar et al., (2014) whereas, this is the first report using Assam rice cultivars in elite genetic background.

The QTL for grain yield per plant ( $q G Y P 7.1)$ was identified on chromosome 7 in the marker interval of RM2 and RM11 under drought stress (Fig. 2). The allele responsible for high grain yield was contributed by drought tolerant parent 'Banglami'.

However, under irrigated conditions another QTL for grain yield ( $q$ GYP9.1) was identified on chromosome 9 flanked by RM553RM205. The allele was contributed by high yielding drought susceptible parent 'Ranjit'. A cluster of grain yield related QTLs on the long arm of chromosome 9 was also reported by Xie et al., (2008). 
Table.1 Mean performance of $\mathrm{F}_{4}$ plants raised from Banglami x Ranjit for various yield traits under two hydrological conditions Drought stress

\begin{tabular}{|c|c|c|c|c|c|c|c|c|c|c|}
\hline Genotypes & DTF & NOT & EBT & PH(cm) & PL(cm) & NOG & NOC & SF & GY (g/p) & RLWC \\
\hline Ranjit & 161.00 & 10.25 & 6.00 & 69.00 & 12.50 & 21.00 & 72.00 & 22.58 & 4.50 & 57.14 \\
\hline Sahbhagi Dhan & 128.00 & 8.75 & 7.25 & 87.38 & 21.00 & 70.00 & 15.50 & 81.87 & 15.50 & 72.45 \\
\hline Nerica & 125.00 & 11.00 & 8.25 & 66.50 & 21.00 & 55.00 & 34.50 & 61.45 & 9.00 & 82.45 \\
\hline ARC10372 & 103.00 & 6.23 & 5.15 & 95.38 & 19.50 & 68.00 & 16.00 & 80.95 & 9.00 & 75.68 \\
\hline Banglami & 110.00 & 6.75 & 5.25 & 90.00 & 18.75 & 73.00 & 13.00 & 84.88 & 10.00 & 70.00 \\
\hline Population mean & 123.93 & 11.99 & 8.06 & 91.75 & 18.07 & 38.24 & 28.06 & 56.91 & 7.65 & 60.88 \\
\hline B-42 & 124.00 & 10.20 & 8.60 & 88.25 & 23.50 & 97.40 & 20.50 & 82.61 & 17.50 & 69.43 \\
\hline B-106 & 125.00 & 11.50 & 10.00 & 108.25 & 22.50 & 101.25 & 23.75 & 81.00 & 19.00 & 71.75 \\
\hline Heritability & 0.97 & 0.96 & 0.92 & 0.99 & 0.98 & 0.99 & 0.99 & 0.99 & 0.98 & 0.99 \\
\hline C.D. @5\% & 2.37 & 0.89 & 1.30 & 0.64 & 0.84 & 1.15 & 1.14 & 0.99 & 0.57 & 0.91 \\
\hline
\end{tabular}

\section{Irrigated condition}

\begin{tabular}{|c|c|c|c|c|c|c|c|c|c|c|}
\hline Genotypes & DTF & NOT & EBT & PH(cm) & $\mathrm{PL}(\mathrm{cm})$ & NOG & NOC & SF & GY (g/p) & RLWC \\
\hline Ranjit & 153.00 & 32.00 & 27.00 & 102.33 & 24.00 & 147.60 & 20.00 & 88.07 & 25.00 & 59.98 \\
\hline Sahbhagi Dhan & 135.00 & 6.25 & 5.75 & 114.00 & 28.00 & 71.00 & 12.00 & 85.54 & 18.00 & 66.10 \\
\hline Nerica & 132.00 & 12.50 & 12.25 & 89.50 & 23.75 & 59.50 & 24.00 & 71.26 & 14.00 & 78.57 \\
\hline ARC10372 & 110.00 & 5.50 & 5.00 & 101.00 & 22.25 & 34.00 & 8.00 & 80.95 & 11.34 & 73.33 \\
\hline Banglami & 117.00 & 11.75 & 11.00 & 100.25 & 21.75 & 56.50 & 8.50 & 86.92 & 12.56 & 58.49 \\
\hline Population mean & 130.91 & 16.21 & 14.60 & 109.98 & 23.12 & 59.35 & 35.29 & 62.62 & 16.79 & 69.45 \\
\hline B-42 & 131.00 & 19.25 & 18.00 & 115.00 & 22.50 & 56.50 & 8.30 & 87.19 & 20.00 & 66.67 \\
\hline B-106 & 132.00 & 10.50 & 9.25 & 121.50 & 23.25 & 66.50 & 12.00 & 84.71 & 21.50 & 61.25 \\
\hline Heritability & 0.98 & 0.98 & 0.96 & 0.99 & 0.85 & 0.99 & 0.99 & 0.99 & 0.99 & 0.99 \\
\hline C.D.@5\% & 1.70 & 1.10 & 1.39 & 1.17 & 1.75 & 1.43 & 1.07 & 0.84 & 0.72 & 0.43 \\
\hline
\end{tabular}

DTF- Days to 50\% flowering, NOT- No. of tillers per plant, EBT- Effective booting tillers per plant, PH-Plant Height (cm), PL- Panicle length (cm), NOG- No. of Grains per panicle, NOC- No. of chaffs per panicle, SF- Spikelet fertility (\%), GY- Grain yield per plant, RLWC- Relative leaf water content. C.D- Critical difference. 
Table.2 Correlation coefficient among the yield traits of $\mathrm{F}_{4}$ population raised from 'Banglami and Ranjit' under drought stress

\begin{tabular}{|c|c|c|c|c|c|c|c|c|c|c|}
\hline & DTF & NOT & EBT & $\mathbf{P H}$ & PL & NOG & NOC & SF & GY & RLWC \\
\hline DTF & 1 & & & & & & & & & \\
\hline NOT & -0.121 & 1 & & & & & & & & \\
\hline EBT & $-0.338 *$ & $0.728 * *$ & 1 & & & & & & & \\
\hline $\mathrm{PH}$ & -0.101 & 0.114 & 0.169 & 1 & & & & & & \\
\hline $\mathrm{PL}$ & $-0.243 * *$ & 0.160 & $0.483^{* *}$ & $0.403 * *$ & 1 & & & & & \\
\hline NOG & -0.114 & 0.164 & $0.236 * *$ & 0.146 & $0.338 * *$ & 1 & & & & \\
\hline $\mathrm{NOC}$ & $0.390 * *$ & $-0.222 *$ & $-0.401 * *$ & $-0.229 *$ & $-0.331 * *$ & $-0.241 * *$ & 1 & & & \\
\hline $\mathrm{SF} \%$ & $-0.342 * *$ & $0.285^{* *}$ & $0.450 * *$ & $0.242 * *$ & $0.412 * *$ & $0.703 * *$ & $-0.802 * *$ & 1 & & \\
\hline GY & -0.147 & $0.186^{*}$ & $0.259 * *$ & $0.240 * *$ & $0.292 * *$ & $0.501 * *$ & $-0.253 * *$ & $0.463 * *$ & 1 & \\
\hline RLWC & -0.130 & -0.022 & 0.133 & -0.044 & -0.023 & 0.066 & 0.099 & -0.017 & 0.087 & 1 \\
\hline
\end{tabular}

** Correlation is significant at 0.01 level * correlation is significant at the 0.05 level.

DTF- Days to $50 \%$ flowering, NOT- No. of tillers per plant, EBT- Effective booting tillers per plant, PH-Plant Height (cm), PL- Panicle length (cm), NOG-

Number of Grains per panicle, NOC- Number of chaffs per panicle, SF- Spikelet fertility, GY- Grain yield per plant

RLWC- Relative leaf water content

Table.3 QTL identified for yield traits under drought-stress and irrigated conditions in $\mathrm{F}_{2}$-derived lines from 'Banglami and Ranjit'

\begin{tabular}{|c|c|c|c|c|c|c|c|c|c|}
\hline S. No. & Trait & QTL & Chromo. & Position/ cM & Marker Interval & LOD & Additive & $\mathbf{R}^{2}$ & Method \\
\hline 1 & NOT & $q N O T 2.1-D S$ & 2 & 134.2 & RM341-RM475 & 3.07 & -0.318 & 5.3 & CIM \\
\hline 2 & EBT & $q E B T 6.2-D S$ & 6 & 111.1 & RM400-RM20757 & 2.98 & -0.04 & 0.56 & CIM \\
\hline 3 & EBT & qEBT6.1-IR & 6 & 97.3 & RM30-RM400 & 3.2 & 0.05 & 5 & IM \\
\hline 4 & $\mathrm{PL}$ & $q P N L 1.1-D S$ & 1 & 173.6 & RM5638- RM3614 & 4.03 & 4.67 & 1.5 & IM \\
\hline 5 & $\mathrm{PL}$ & qPNL6.1-DS & 6 & 47.9 & RM253- RM30 & 6.96 & 5.19 & 6.9 & IM \\
\hline 6 & $\mathrm{NOG}$ & $q N O G 12.1-D S$ & 12 & 16 & RM7003- RM1261 & 6.35 & 20.1 & 84 & CIM \\
\hline 7 & $\mathrm{NOC}$ & $q N O C 6.1-D S$ & 6 & 59.9 & RM253- RM30 & 2.92 & 12.34 & 83 & CIM \\
\hline 8 & $\mathrm{NOC}$ & $q N O C 4.1-I R$ & 4 & 101.5 & RM303- RM127 & 3.02 & -12.35 & 6.4 & CIM \\
\hline 9 & $\mathrm{SF}$ & qSFP6.1-IR & 6 & 60.9 & RM253-RM30 & 3.81 & 2.04 & 0.4 & CIM \\
\hline 10 & GY & $q G Y P 7.1-D S$ & 7 & 56.8 & RM2- RM11 & 3.89 & 1.58 & 23 & CIM \\
\hline 11 & GY & $q G Y P 9.1-I R$ & 9 & 70.1 & RM553-RM205 & 3.04 & -1.45 & 0.04 & IM \\
\hline
\end{tabular}

NOT- No. of tillers per plant, EBT- No. of effective booting tillers per plant, PL- Panicle length (cm), NOG- Number of Grains per panicle, NOC- Number of chaffs per panicle, SF- Spikelet fertility, GY- Grain yield per plant, LOD- Logarithm of Odds, CIM- Composite Interval Mapping, IM- Interval Mapping, DSDrought stress, IR- Irrigated conditions 
Fig.1 The $\mathrm{F}_{4}$ population raised from 'Banglami $\mathrm{x}$ Ranjit' under reproductive stage Drought stress in rainout shelter

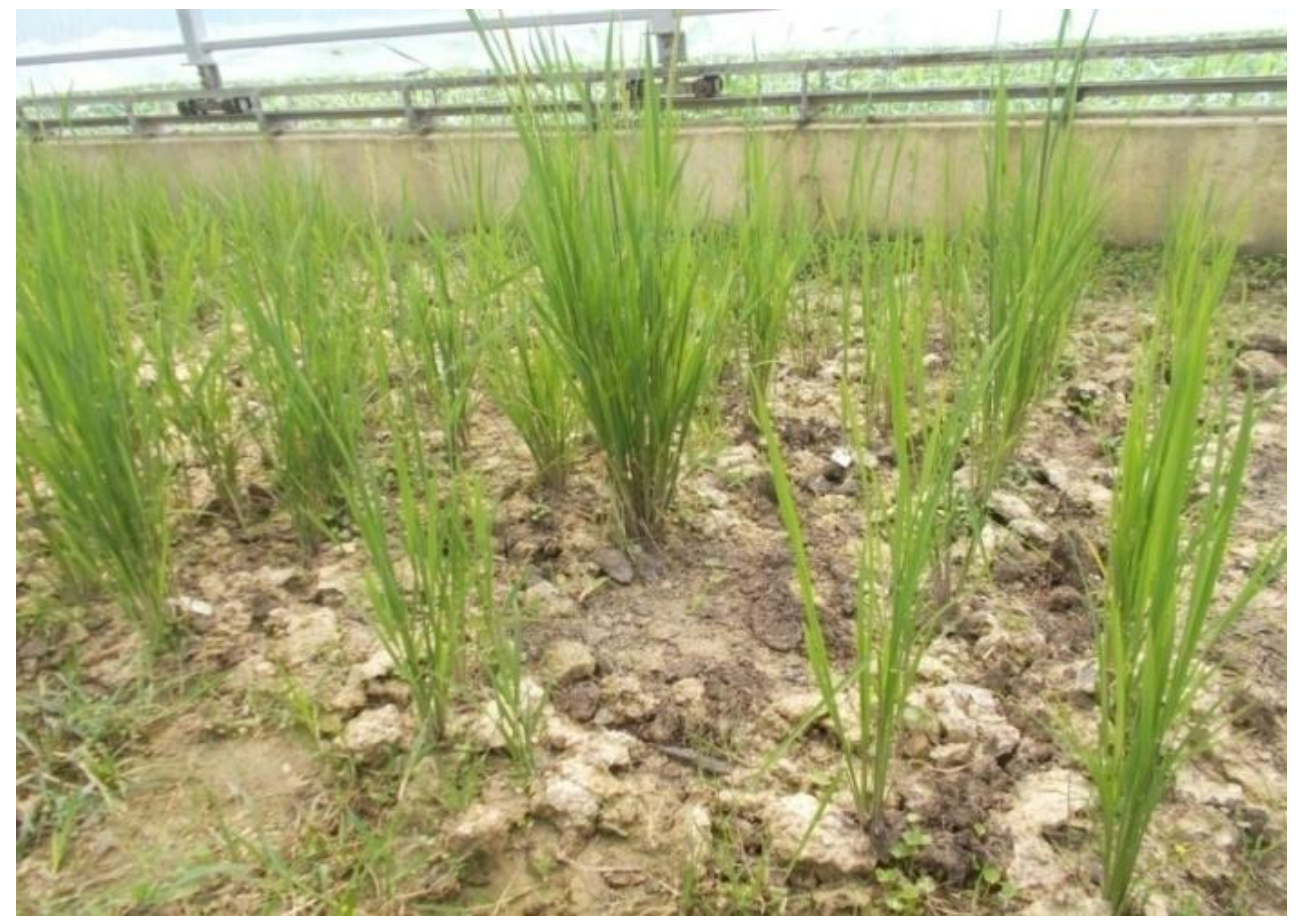

Fig.2 QTL likelihood curves of the LOD score for grain yield per plant ( $q$ GYP7.1) on chromosome 7 under drought stress

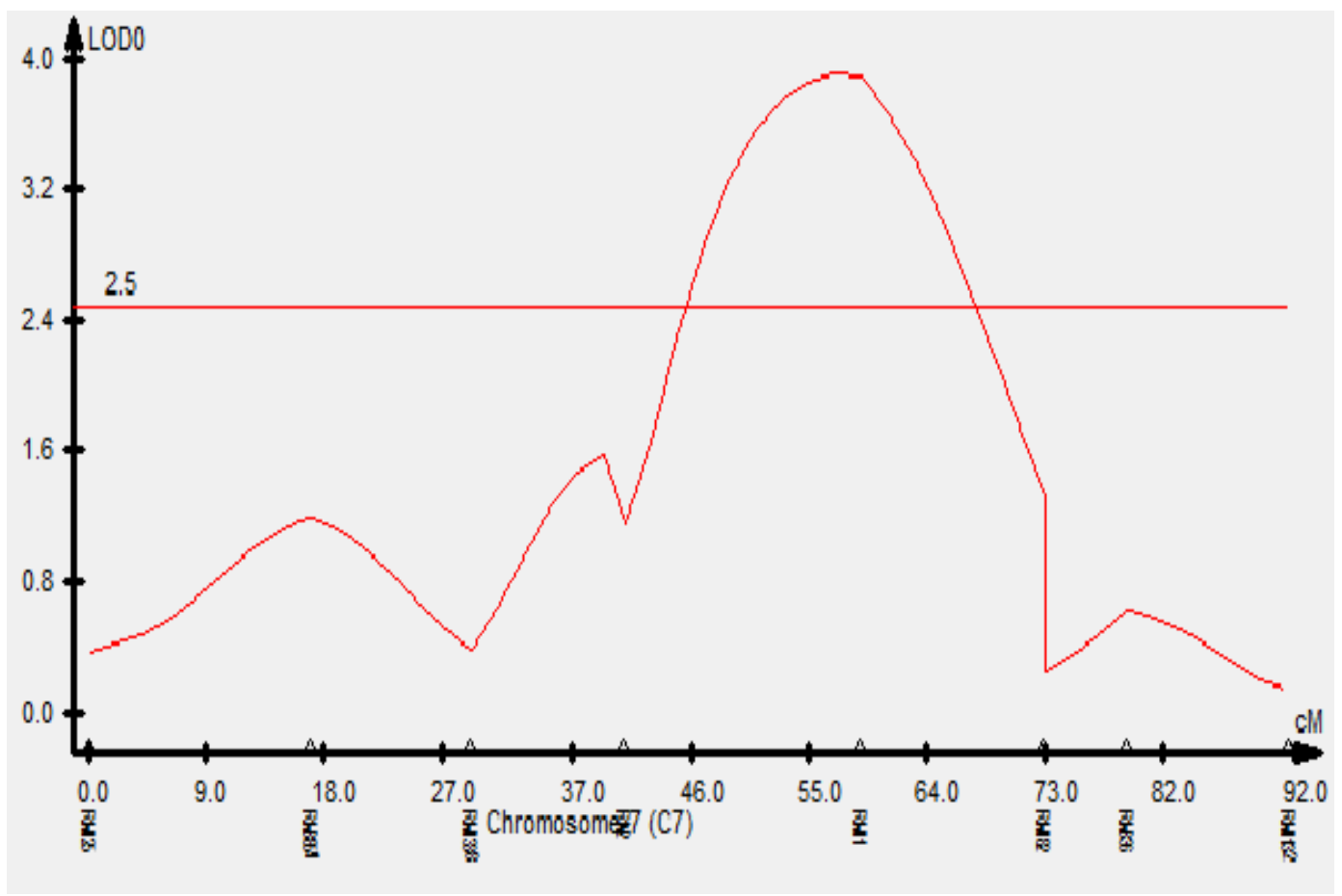


Fig.3 QTL likelihood curves of the LOD score for number of grains per panicle (qNOG12.1) on chromosome 12 under drought stress

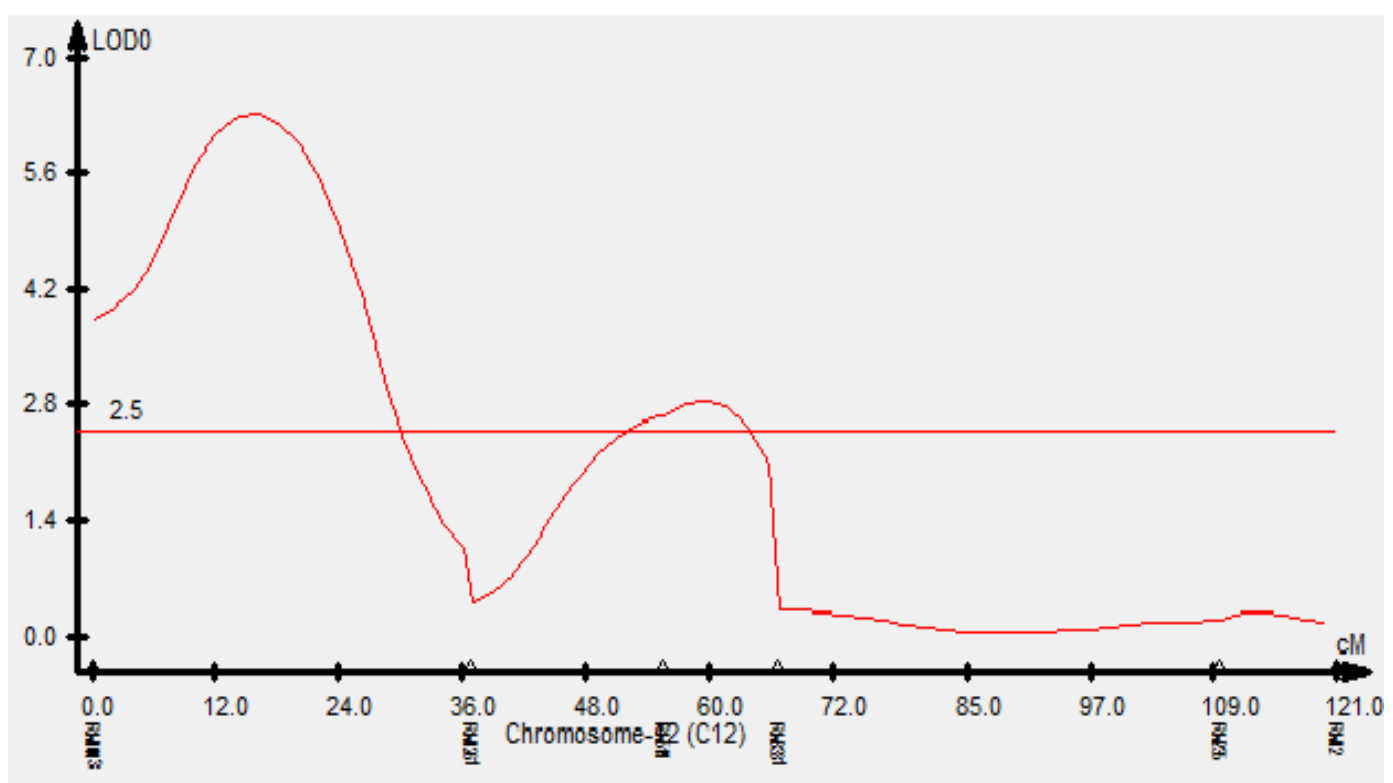

The QTL for number of tillers per plant (qNOT2.1) was identified on chromosome 2 between the marker interval of RM341 and RM475, the favourable allele was contributed by high yielding drought susceptible parent 'Ranjit'. Marker RM475 has also been reported to be associated with grain yield, days to 50 per cent flowering, harvest index, and biomass under varying stress levels in upland conditions (Dixit et al., 2012).The QTL for effective booting tillers (qEBT6.2) was identified on chromosome 6 flanked by SSR markers RM400 and RM20757 under drought stress; it was contributed by susceptible parent 'Ranjit'. However, under irrigated conditions another QTL (qEBT6.1) was identified on the same chromosome 6 between the SSR markers RM30 and RM400. The allele contributing parent was 'Banglami'. The QTLs under two hydrological conditions remained consistent and located adjacent to RM400 on the same chromosome. It indicates that QTLs are stable on the same chromosome and not essentially affected by environmental factors also reported by Suji et al., (2012).
Two QTLs were identified for panicle length under drought stress. A QTL ( $q$ PNL1.1) was located on chromosome 1 in the marker interval of RM5638-RM3614 contributed by female parent 'Bangalmi'. This region is also associated with a grain yield QTL ( $q D T Y 1.2)$ (Sandhu et al., 2014), QTLs for root traits (Gomez et al., 2010), Plant height (Bernier et al., 2007), root dry weight (Zhang et al., 2001), grains per panicle (Babu et al., 2003), relative water content (Kanbar et al., 2002), biomass, basal root thickness, and osmotic adjustment (Robin et al., 2003) under drought stress. Another QTL for panicle length (qPNL6.1) was identified on chromosome 6 spanned by RM253-RM30. The favourable allele at this locus was contributed by the drought tolerant parent 'Banglami'.

The QTL for number of grains per panicle (qNOG12.1) was identified on chromosome 12 flanked by RM7003-RM1261 under drought stress (Fig. 3). It was contributed by tolerant parent 'Banglami'. Marker RM1261 has been reported to be associated with grain yield QTL (qDTY12.1) under drought stress 
(Bernier et al., 2007). The QTL for number of chaff per panicle (qNOC6.1) was identified on chromosome 6 flanked by RM253 and RM30 under drought stress. The allele contributing parent was 'Banglami'. However, under irrigated conditions a QTL (qNOC4.1) was identified on chromosome 4 in the marker interval of RM303-RM127. It was contributed by the parent 'Ranjit'. A QTL for number of chaff per panicle on chromosome 6 under non stress conditions was also reported by Muthukumar et al., (2015). Under irrigated conditions a QTL for spikelet fertility (qSFP6.1) was identified on the chromosome 6 flanked by RM253-RM30. The allele was contributed by tolerant parent 'Banglami'. Muthukumar et al., (2015) also reported a QTL for spikelet fertility on chromosome 6 under non stress conditions.

\section{Clustering of QTLs}

Highly correlated traits are expected to have overlapping QTLs located on the same chromosomal regions as reported by Babu et al., (2003). In the present study significant correlation was observed among the traits i.e., panicle length, number of chaff per panicle and spikelet fertility resulting in clustering of their QTLs on chromosome 6 in the same marker interval of RM253-RM30. Clustering of QTLs were also reported earlier in rice (Hittalmani et al., 2002 and Zou et al., 2005) indicating tight linkage of different polygenes could be the possible reasons for the congruence of several QTLs. Another reason for the coincidence of QTLs is that character correlation may be attributed to the effect of pleiotropy or even very close linkage of genes (Lin et al., 1996).

The QTL and environment interactions have always played a major role in the development of drought-tolerant crop varieties. The effect of the same QTL varies with the environment in which it is detected.
In order to overcome this effect, local cultivars suitable for the target environment were used in the present study for the development of mapping population. This is the first report of QTL mapping for grain yield and its component traits under drought stress in Assam rice cultivars. Therefore; the identified QTLs can be successfully exploited using MAB for the improvement of grain yield in high yielding drought susceptible varieties under drought stress, the large number of progenies from the selected lines (B-42, B-106) to be raised and evaluated in subsequent generation in order to develop drought tolerant rice variety in elite genetic background.

\section{Acknowledgement}

The authors gratefully acknowledge DBTAAU Centre for providing the financial assistance to RV, Dr. B.K. Sarmah, Director, DBT-AAU Centre for all-round support also to Dr. T. Ahmed, Chief Scientist, RARS, Titabar for providing the logistic support to the field work.

\section{References}

Babu, R.C., Nguyen, B.D., Chamarerk, V., Shanmugasundaram, P., Chezhian, P., Jeyaprakash, P., Ganesh, S.K., Palchamy, A., Sadasivam, S., Sarkarung, S., Wade, L.J. and Nguyen, H.T. 2003. Genetic analysis of drought resistance in rice by molecular markers: Association between secondary traits and field performance. Crop Sci., 43: 1457-1469.

Basten, C., Weir, B. and Zeng, Z.B. 2001. QTL Cartographer. Department of Statistics, North Carolina State University, Raleigh, NC

Bernier, J., Atlin, G.N., Serraj. R., Kumar. A. and Spaner D. 2008. Breeding upland 
rice for drought resistance. J. Sci. Food Agric., 88: 927-939

Bernier, J., Kumar, A., Venuprasad, R., Spaner, D. and Atlin, G.N. 2007. A large-effect QTL for grain yield under reproductive-stage drought stress in upland rice. Crop Sci., 47: 507-516

Dixit, S., Swamy, B.P.M., Vikram, P., Bernier, J., Sta Cruz, M.T., Amante, M., Atri, D. and Kumar, A. 2012. Increased drought tolerance and wider adaptability of qDTY12.1 conferred by its interaction with qDTY2.3 and qDTY3.2. Mol. Breed., 30: 1767-1779

Gomez, M.S., Boopathi, N.M., Kuma, S.S., Ramasubramanian, T., Chengsong, Z., Jeyaprakash, P., Senthil, A. and Babu, R.C. 2010. Molecular mapping and location of QTLs for drought-resistance traits in indica rice (Oryza sativa L.) lines adapted to target environments. Acta. Physiol. Plant, 32: 355-364

Hackett, C.A. and Broadfoot, L.B. 2003. Effects of genotyping errors, missing values and segregation distortion in molecular marker data on the construction of linkage maps. Heredity, 90: 33-38

Hittalmani, S., Shashidhar, H., Bagali, P.G., Huang, N., Sidhu, J., Singh, V. and Khush, G. 2002. Molecular mapping of quantitative trait loci for plant growth, yield and yield related traits across three diverse locations in a doubled haploid rice population. Euphytica, 125: 207214

Jongdee, B., Fukai, S. and Cooper, M. 2002. Leaf water potential and osmotic adjustment as physiological traits to improve drought tolerance in rice. Field Crops Res., 76: 153-163.

Kanbar, A., Shashidhar, H.E. and Hittalmani, S. 2002. Mapping of QTL associated with root and related traits in $\mathrm{DH}$ population of rice (Oryza sativa L). Indian J. Genet., 62: 287-290.
Kosambi, D.D. 1944. The estimation of map distances from recombination values. Ann. Eugen., 12: 172-175

Kumar, A., Dixit, S., Ram, T., Yadaw, R.B., Mishra, K.K. and Mandal, N.P. 2014. Breeding high-yielding drought-tolerant rice: genetic variations and conventional and molecular approaches. J. Exp. Bot., 65: 6265-6278.

Kumar, A., Bernier, J., Verulkar, S., Lafitte, H.R. and Atlin, G.N. 2008. Breeding for drought tolerance: direct selection for yield, response to selection and use of drought-tolerant donors in upland and lowland-adapted populations. Field Crop. Res., 107: 221-231.

Lafitte, H.R., Price, A.H. and Courtois, B. 2004. Yield response to water deficit in an upland rice mapping population: associations among traits and genetic markers. Theor. Appl. Genet., 109: 1237-1246.

Lafitte, R., Bennett, J. and Kathiresan, A. 2006. Drought adaptation in rice. In: Drought Adaptation in Cereals, Ribaut, J.M. (ed.) Haworth Press, Inc., New York, pp. 301-334

Lin, H.X., Qian, H.R., Zhuang, J.Y., Lu, J., Min, S.K. and Xiong, Z.M. 1996. RFLP mapping of QTLs for yield and related characters in rice (Oryza sativa L.). Theor. Appl. Genet., 92: 920-927.

Liu, J.K., Liao, D.Q., Oane, R., Estenor, L., Yang, X.E., Li, Z.C. and Bennett, J. 2006. Genetic variation in the sensitivity of anther dehiscence to drought stress in rice. Field Crop Res., 97: 87-100.

Lorieux, M., Goffinet, B., Perrier, X., Gonzalez, D.L. and Lanaud, C. 1995. Maximum likelihood models for mapping genetic markers showing segregation distortion. 1. Backcross populations. Theor. Appl. Genet., 90: 73-80. 
Muthukumar, C., Deshmukh, V., Vivek., Poornima, R., Kavitha, S., Gayathri V. and Babu, R.C. 2015. Fine mapping of consistent quantitative trait loci for yield under drought stress using rice (Oryza sativa L) recombinant inbred lines adapted to rainfed environment. Curr. Sci., 109.

Pantuwan, G., Fukai, S., Cooper, M., Rajatasereekul, S. and O'Toole, J.C. 2002. Yield response of rice (Oryza sativa L.) genotypes to drought under rainfed lowlands. Selection of drought resistant genotypes. Field Crop Res., 73: $169-80$.

Plaschke, J., Ganal, M.W. and Roder, M.S. 1995. Detection of genetic diversity in closely related bread wheat using microsatellite markers. Theor. Appl. Genet., 91: 1001-1007

Richards, R.A., Rebetzke, G.J., Watt, M., Condon, A.G., Spielmeye, W. and Dolferus, R. 2010. Breeding for improved water productivity in temperate cereals: phenotyping, quantitative trait loci, markers and the selection environment. Func. Plant Biol., 37: 85-97

Robin, S., Pathan, M.S., Courtois, B., Lafitte, R., Carandang, S., Lanceras, S., Amante, M., Nguyen, H.T. and Li, Z.K. 2003. Mapping osmotic adjustment in an advanced backcross inbred population of rice. Theor. Appl. Genet., 107: 1288-1296.

Sandhu, N., Singh, A., Dixit, S., Sta Cruz, MT., Maturan, P.C., Jain, R.K. and Kumar A. 2014. Identification and mapping of stable QTL with main and epistasis effect on rice grain yield under upland drought stress. BMC Genet., 15: 63.

Sellamuthu, R., Liu, G.F., Ranganathan, C.B. and Serraj, R. 2011. Genetic analysis and validation of quantitative trait loci associated with reproductive-growth traits and grain yield under drought stress in a doubled haploid line population of rice (Oryza sativa L.). Field Crop Res., 124: 46-58.

Servin, B., Martin, O.C., Mezard, M. and Hospital F. 2004. Toward a theory of marker-assisted gene pyramiding. Genetics, 168: 513-23.

Stam, P. 1993. Construction of integrated genetic linkage maps by means of a new computer package: Join Map. Plant J., 3: 739-744.

Suji, K.K., Biji, K.R., Poornima, R., Prince, K.S.J., Amudha, K., Kavitha, S., Mankar, S. and Babu, R.C. 2012. Mapping QTLs for plant phenology and production traits using indica rice (Oryza sativa L.) lines adapted to rainfed environment. Mol. Biotechnol., 52: 151-160.

Venuprasad, R., Lafitte, H.R. and Atlin, G.N. 2007. Response to direct selection for grain yield under drought stress in rice. Crop Sci., 47: 285-293.

Verulkar, S.B., Mandal, N.P., Dwivedi, J.L., Singh, B.N., Sinha, P.K., Mahato, R.N., Dongre, P., Singh, O.N., Bose, L.K., Swain, P., Robin, S., Chandrababu, R., Senthil, S., Jain, A., Shashidhar, H.E., Hittalmani, S., Vera Cruz, C., Paris, T., Raman, A., Haefele, S., Serraj, R., Atlin, G. and Kumar, A. 2010. Breeding resilient and productive genotypes adapted to drought-prone rainfed ecosystem of India. Field Crops Res., 117: 197-208.

Vikram, P., Mallikarjuna Swamy, B.P., Dixit, S., Ahmed, H.U., Sta Cruz, M.T., Singh, A.K. and Kumar A. 2011. qDTY1.1, a major QTL for rice grain yield under reproductive-stage drought stress with a consistent effect in multiple elite genetic backgrounds. BMC Genet., 12: 89.

Xie, X., Jin, F., Song, M.H., Suh, J.P., Hwang, H.G., Kim, Y.G., McCouch, 
S.R. and Ahn, S.N. 2008. Fine mapping of a yield-enhancing QTL cluster associated with transgressive variation in an Oryza sativa L. 9 O. rufipogon cross. Theor. Appl. Genet., 116: 613622.

Zhang, J., Zheng, H., Aarti, A., Pantuwan, G., Nguyen, T., Tripathy, J., Sarial, A., Robin, S., Babu, R. and Nguyen, B.D. 2001. Locating genomic regions associated with components of drought resistance in rice: comparative mapping within and across species. Theor. Appl. Genet., 103: 19-29

Zhuang, J.Y., Fan, Y.Y., Rao, Z.M., Wu, J.L., Xia, Y.W. and Zheng, K.L. 2002. Analysis on additive effects and additiveby-additive epistatic effects of QTLs for yield traits in a recombinant inbred line population of rice. Theor. Appl. Genet., 105: 1137-1145

Zivy, M., Devaux, P., Blaisonneaux, J., Jean, R. and Thiellement, H. 1992. Segregation distortion and linkage studies in microspore-derived double haploid lines of Hordeum vulgare L. Theor. Appl. Genet., 83: 919-924

Zou, G.H., Mei, H.W., Liu, H.Y., Liu, G.L., $\mathrm{Hu}$, S.P. and Yu, X. 2005. Grain yield responses to moisture regimes in a rice population: association among traits and genetic markers. Theor. Appl. Genet., 112: 106-113.

\section{How to cite this article:}

Rahul K. Verma, S.K. Chetia, P.C. Dey, A.R. Baruah and Modi, M.K. 2017. Mapping of QTLs for Grain Yield and Its Component Traits under Drought Stress in Elite Rice Variety of Assam. Int.J.Curr.Microbiol.App.Sci. 6(6): 1443-1455. doi: https://doi.org/10.20546/ijcmas.2017.606.169 